\title{
The Effects of Work-Child Education Conflict on Parenting Role Competence of Working Mothers of Second Graders: Focus on the Moderating Effect of Mother-Child Identification
}

\author{
Eun Hwa Jeong ${ }^{1}$, Ji Young Kim², Hyun A Lee ${ }^{3}$, Kangyi Lee ${ }^{4}$ \\ M. A. Student, Department of Child Development and Family Studies, Seoul National University, Seoul, Korea ${ }^{1}$ \\ Ph. D. Student, Department of Child Development and Family Studies, Seoul National University, Seoul, Korea ${ }^{2}$ \\ M. A. Student, Department of Interdisciplinary Program in Early Childhood Education, \\ Seoul National University, Seoul, Korea ${ }^{3}$ \\ Professor, Department of Child Development and Family Studies, Seoul National University \& Adjunct Researcher, \\ Research Institute of Human Ecology, Seoul National University, Seoul, Korea ${ }^{4}$

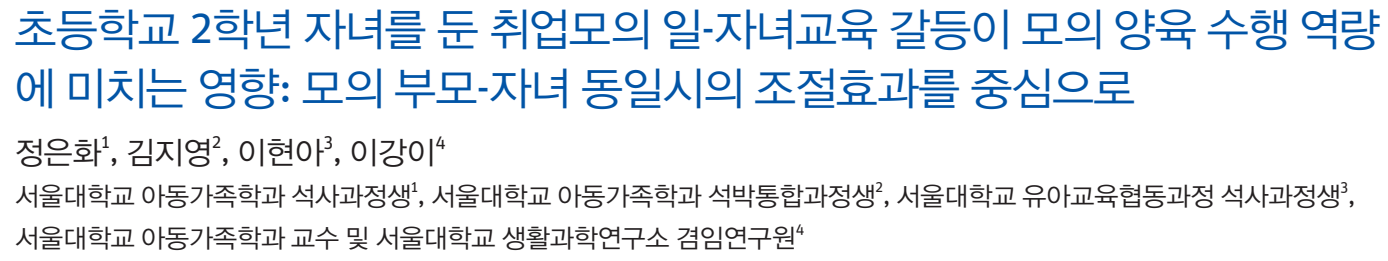

Objectives: The purpose of this study was to examine the moderating effect of mother-child identification on the relationship between work-child education conflict and parenting role competence.

Methods: Descriptive statistics, Pearson's correlation, and hierarchical regression were used to analyze data on 155 mothers of children aged 8 years from the Panel Study of Korean Parental Educational Involvement (PSKPEI) in 2018 (2nd year).

Results: First, the work-child education conflict of mothers had a significant negative influence on their parenting role competence. Second, the mother-child identification had a significant positive effect on their parenting role competence. Finally, the moderating effect of work-child education conflict and mother-child identification on parenting role competence was significant. A working mother with a high level of mother-child identification represented a relatively high level of parenting role competence, even though they experienced severe work-child education conflict.

Conclusion: In the background of a Korean culture where parents identify with their children, this study revealed how much working mothers are willing to make sacrifices for their children, even though work-child education is incompatible. It also proposed the need for policy and social support to assist them as parents.

Keywords: working mothers, work-child education conflict, parenting role competence, mother-child identification

Corresponding Author: Ji Young Kim, Ph. D. Student, Department of Child Development and Family Studies, Seoul National University, 1, Gwanakro, Gwanak-gu, Seoul, Korea

E-mail: wuddl012@snu.ac.kr
(C)The Korean Association of Child Studies

This is an Open Access article distributed under the terms of the Creative Commons Attribution Non-Commercial License (http:// creativecommons.org/licenses/by-nc/4.0) which permits unrestricted noncommercial use, distribution, and reproduction in any medium, provided the original work is properly cited. 


\section{Introduction}

예로부터 '맹모삼천지교(孟母三遷之㸚)'라는 말이 있었고, 요 즘에는 다양한 주제의 자녀교육서가 쏟아져 나오고 있다. 이 와 같이 예나 지금이나 건강하고 행복한 아이들을 기를 수 있 는 바람직한 부모의 역할의 중요성이 강조되어 왔다. 특히 요 즘 같이 다변하는 현대 사회에서 성공적인 자녀 양육을 위해 부모의 책임감과 유능성이 과도하게 요구되기도 하는데, 이러 한 요구는 높은 교육열과 만나 때로는 자녀에 대한 지나친 부 모의 개입으로 변질되기도 한다. 이러한 부모들을 풍자하며 그려냈던 JTBC드라마 '스카이 캐슬' 이후 오히려 입시 코디와 250 만 원짜리 뒤주 책상에 대한 문의가 늘었다는 기사(Jang, 2019)가 이를 반증한다. 이러한 사회적 현상은 부모가 어떻게 해서든 자녀를 성공시키고자 하는 열망에 그 근간이 있다.

이는 한국 고유의 문화에 기인한 것으로, 개별성과 독립성 을 강조하는 서구의 개인주의 문화와는 달리 우리나라 부모자녀관계는 관계주의 문화의 특성을 가지고 있다(I. J. Choi, 2006). 우리나라 부모들은 자녀의 성공을 개인의 문제가 아 닌 가족 혹은 집안 전체의 문제로 여기는 경향이 강한데, 이는 자녀의 기쁨과 고통이 부모의 것으로 인식되고, 반대로 부모 의 기쁨과 고통은 곧 자식의 것으로 여겨지는 '부모-자녀 동일 체 의식'을 바탕으로 가지고 있기 때문이다(J. Han, Kim, Kim, \& Song, 2013). 따라서 실제로 우리나라 대다수 부모들은 자 신의 사회경제적 지위보다 자녀가 더 높은 수준을 성취하기 를 바라며, 자녀교육을 통해 계층상승을 이루기를 기대한다 (Y. J. Jeong, 1978). 또한 자녀들이 높은 성과를 거둔 것에 대해 부모들은 자신의 인생에서 가장 소중한 성취로 인식할 가능성 이 높다(C. S. Lee, 2011). 이러한 ‘부모-자녀 동일시’를 바탕으 로 갖는 자녀에 대한 부모의 기대는 성장기 자녀의 성격 형성 또는 지적 발달에 영향을 미치는 중요한 요소이며(S. Y. Han, 2006), 이러한 기대가 있기에 부모들은 자녀를 위해 희생이나 고통을 감수한다.

이러한 부모들은 자녀를 위한 부모로서의 역할을 감당하 기 위해 정서적으로 뿐만 아니라 물질적으로 자녀를 지원하 고자 한다. 실제로 통계청(Statistics Korea, 2019)의 '2018년 하 반기 지역별 고용조사(부가항목)-맞벌이 가구 및 1 인 가구 고 용 현황'에 따르면 자녀의 연령이 높아질수록 맞벌이 비중 도 높아졌다. 이와 같이 연령이 증가할수록 맞벌이 비율이 높 아지는 현상에 대하여 자녀 성장에 따라 교육비가 많이 필요 하기 때문이라고 언론들은 지적하고 있다(E. Chung, 2019; Kang, 2017). 또한 리서치 기업인 트렌드모니터(Embrain Trend
Monitor, 2012)는 맞벌이를 하고 있는 사람들은 자녀 양육비 부담(61.2\%, 중복응답)을 맞벌이의 가장 큰 이유로 꼽았다. 통 계청(Statistics Korea, 2015)의 가계동향조사에 따르면, 소비지 출 항목 중 대부분 항목에서 맞벌이가 외벌이보다 많이 쓰고 있는데, 특히 교육비 항목에서 맞벌이 가정이 매월 11만원씩 더 지출하는 것으로 나타나 가장 큰 차이를 보였다. 이를 통해 유자녀 여성들이 취업하는 큰 이유 중 하나는 자식을 잘 키우 고자 하는 바람 때문이며, 취업모의 대부분이 일과 자녀교육 에 대한 부담 모두를 가지고 있을 것임을 유추할 수 있다.

실제로 많은 맞벌이 가정에서 취업한 여성으로서의 어머니 는 부모로서의 역할과 직장인으로서의 역할을 동시에 감당하 고 있다. 2014년 통계청(Statistics Korea, 2015)에서 실시한 생 활시간 조사에 따르면 취업모는 남성보다 가정관리에 약 2시 간이나 더 소요하여 취업모는 직장과 가정 업무를 병행해야 함을 알 수 있다. 일반적으로 이중의 역할이 요구되는 취업모 에게 있어서 보통의 경우 직장에서 기대되는 역할과 가정에 서 기대되는 역할은 서로 양적, 시간적, 심리적 측면에서 대립 적인 관계이기 쉽다(H. J. Park \& Moon, 2012). 따라서 가정일 에 몰두하다 보면 직장 내 역할 수행에 희생을 초래하며 직장 에의 몰두는 가정 내 역할 수행에 차질을 가져올 수 있는데, 이 러한 갈등을 ‘일-가정 갈등'이라고도 한다(Duxbury, Higgins, \& Lee, 1994). 결국 취업모는 가정에서는 '엄마'로서의 역할을 수 행해야 하고, 직장에서도 특별한 배려의 대상이 되지 않도록 노력하며 역할 갈등을 겪게 된다(S. Y. Kim, Kim, \& Lee, 2011). 그런데 특히 취업모에게 가장 부담으로 작용하는 부분은 자녀 양육에 관한 것으로, 가사노동의 경우 처리 가능한 영역인 반 면, 자녀양육에 가장 부담을 느낀다는 선행 연구들이 있다(J. S. Choi, 2011; Hwang \& Shin, 2009; M. S. Kim, 2005). 그럼에 도 불구하고 특히 일-가정 역할 갈등 중 자녀교육 측면에서 부 모로서 느끼는 갈등에 대한 연구는 부족한 실정이다. 따라서 본 연구에서는 일-가정 역할 갈등 중 '일-자녀교육 갈등'에 중 점을 두어 논의를 전개하고자 한다.

특히 한국사회의 자녀교육과 관련된 어머니의 역할은 더 욱 과중해졌는데, 단순히 자녀를 '낳아놓기'만 하면 되는 것 이 아니라 '잘 키우는 것'이 강조되는 현대 사회에서(A. Cho, 2005), 양육과 관련된 부모의 역량이 강조되고 있다. 부모가 자신의 삶에 대해 높은 내적동기를 가지고 가변적 상황에 능 숙하게 대처 및 통제하며, 필요한 자원과 지지를 적절하게 획 득하는 능력은 중요하다(Murray, Handyside, Straka, \& ArtonTitus, 2013; J. Park, Seo, \& Kim, 2013). 특히 양육역량(parenting competency)은 양육(parenting)과 역량(competence)의 합성어 
로 부모의 역할을 성공적으로 수행하는 능력이다(H.-S. Cho \& Kim, 2013). 부모의 양육역량은 자녀양육에 있어 자신감이 있고 잘 해내고 있다고 인식하는 측면으로, 양육스트레스와 같은 심리.정서적 문제에 영향을 받는다(M.-R. Chung, Cha, $\mathrm{Ju}, \& \mathrm{Kim}, 2015)$. 또한 부모 자신의 양육역량에 관한 인식은 양육행동에도 직접적인 영향을 미치고(Abidin, 1992), 부모 개 인의 역할만족 뿐 아니라 자녀의 발달까지 영향을 미칠 수 있 는 요인이 된다(M.-R. Chung et al., 2015). 즉, 일과 육아의 부 담이 과중한 가운데, 양육역량을 통해 형성된 스스로 잘 해낼 수 있다는 취업모의 자신감과 능력은 삶의 동력에 매우 중요 한 요소이다(M.-R. Chung et al., 2015). 이러한 맥락에서 양육 역량에 대해 살펴 볼 필요가 있다.

특히, J. Park, Seo와 Kim (2013)은 양육역량을 부모가 자녀 를 양육함에 있어 자녀의 특성과 발달에 대해 이해하는 '양육 기반 역량'과 자녀의 발달을 지원하는 환경을 제공하고, 반응 적이고 민주적인 양육을 행하여 부모로서의 자신에 대해 만 족감을 느끼는 양육 실행에 관한 역량인 '양육 수행 역량'으로 나누어 설명하였다. 본 연구에서는 일-자녀교육 역할 갈등이 실질적으로 부모가 자녀와 관계를 맺고 양육을 실행함에 있 어서 어떠한 영향을 미치는지를 파악하고자 하므로, 양육 수 행 역량에 초점을 맞추고자 한다. 어머니의 양육 수행 역량은 학령기 초기에 중요하게 요구되는데, 이는 아동이 여전히 신 체, 인지 및 사회적 발달 중에 있고(K.-S. Chung, Goh, Park, \& Cha, 2014), 특히 유아기에 비하여 또래 상호작용의 범위가 넓 어지면서 더욱 독립적인 인격체가 되기 때문이다(Furman \& Buhrmester, 1992).

이러한 상황에서 우리 사회의 취업모들이 겪는 일-자녀교 육 갈등이 다음의 과정을 통해 양육 수행 역량에 영향을 미칠 수 있음을 예측할 수 있다. 취업모가 직장일이 과중하여 자녀 를 충분히 돌보지 못한다고 느낄 때 자녀양육과 관련한 스트 레스가 증가한다(A.-N. Kim \& Kwon, 2014; B. S. Park \& Um, 2016; M. Yoo, 2014). 이러한 스트레스는 양육태도도 변화시키 는데 J.-M. Kim과 Choi (2018)에 따르면 취업모의 일-가정(자 녀교육) 역할 갈등 수준이 높을수록 애정적 양육태도는 약화 되는 반면, 거부적 양육태도와 통제적 양육태도는 강화된다. 즉, 취업모가 역할갈등을 많이 지각할수록 양육스트레스는 높 아지고, 결과적으로 스스로가 평가하는 양육 수행 역량은 낮 아지게 된다(M.-R. Chung et al., 2015).

이와 같이 양육 수행 역량이 양육스트레스와 같은 심리.정 서적 문제에 영향을 받게 됨을 고려할 때, 본 논문은 부모-자 녀 동일시가 일-자녀교육 갈등이 양육 수행 역량에 미칠 부정
적 영향을 감소시키는 긍정적 역할을 할 것인지, 아니면 오히 려 과중하게 하는 부정적 역할을 할 것인지 파악하는 데 목적 이 있다. 실제로 부모-자녀 동일시가 높아 자녀에 대한 미래기 대가 높을수록 부모역할 인식수준도 높았고(H. S. Cho, 2013), 부모로서의 역할을 기꺼이 수용하며 자녀양육 상황에서 양 육스트레스를 덜 경험한다고 한다(Y. J. Song, Lee, \& Chun, 2014). 그러나 부모-자녀 동일시가 자녀에 대한 부모의 과잉 기대로 나타날 경우, 이는 부모-자녀 간의 갈등을 발생시키는 중요한 원인이 될 수 있다(J. Han et al., 2013). 이는 부모 자신 이 못 이룬 '한'이나 소망을 자녀에게 전가하여 자녀를 부모의 대리만족의 도구로 여기는 경우로(S. Han, 2008), 자기 생각과 주장이 뚜렷해지는 학령기 자녀는 부모와 부딪히게 된다(K.S. Chung et al., 2014). 이는 부모의 양육 스트레스를 높이고(S.M. Kim, 2005), 결국 양육 수행 역량을 낮출 수 있다. 따라서, 부모-자녀 동일시는 일-자녀교육과 양육 수행 역량 사이의 관 계에서 조절효과가 있는지, 있다면 어떠한 방향으로 존재하는 지 주목할 필요가 있다.

본 연구에서는 학령기 진입 시기인 초등학교 저학년을 자 녀로 둔 학부모를 대상으로 하고자 한다. 선행연구에 따르 면 부모-자녀 동일시와 관련하여 대체로 자녀의 학업적 성취 에 대한 부모의 기대가 초등학교부터 시작되며, 학업에 대한 성취압력은 저학년 때부터 매우 높고 진급하여도 가족에 대 한 책임감과 함께 부담감을 줄 수 있으며, 자녀가 부모의 기대 에 부응하지 못했을 때 좌절감을 경험하게 하는 등 부정적 영 향도 미칠 수 있음(Cha, 2011; J. Han et al., 2013; Jeong \& Yoo, 2015)을 고려할 때, 그 시작이 되는 초등학교 저학년 시기를 살펴볼 필요가 있다.

그 중, 특히 초등학교 2학년 학부모를 대상으로 하고자 한 다. Yoon (2016)에 따르면 초등학교 저학년 학부모 $81.9 \%$ 의 응 답자들이 자녀가 초등학교 이전보다 일과 자녀교육을 양립하 기가 더 어려워졌다고 응답했는데, 이는 어린이집, 유치원 등 미취학 아동이 이용하는 시설보다 짧아진 정규 수업시간, 길 어진 학교 자율 휴업일, 방학 등으로 자녀교육에 더 많은 시간 을 할애해야 하기 때문이다. 때문에 초등학교 1학년 시기에 육 아휴직을 사용하는 취업모가 많으며, 정부도 '입학기 아동 부 모 오전 10시 출근제 장려 정책 등으로 지원하고 있다(C. Lee, 2018). 그러나 초등학교 2학년의 경우, 정규 수업 시간은 1 학 년과 동일하여 양육의 어려움은 변함없음에도 불구하고 그러 한 정책이나 지원, 혜택을 받기는 어려워 그 부담이 오롯이 학 부모에게 전가되고 있다. 또한 만 8세 또는 초등학교 2학년 때 까지 육아휴직이 지원되지만, 대부분 변동폭이 큰 1학년 입학 
시기에 육아휴직을 사용하고 2학년 때 복직하는 경우들도 많 다(Hong, 2017). 그럼에도 불구하고 초등학교 2학년 학부모의 취업모로서의 일-자녀교육 갈등에 대한 연구는 부족한 현실 이어서 이에 대한 연구가 필요하다. 이러한 점을 고려할 때 초 등학교 2학년 학부모인 취업모를 대상으로 하여 논의를 진행 하는 것이 본 연구문제에 매우 부합하다고 하겠다.

\section{연구문제 1}

취업모의 일-자녀교육 갈등과 부모-자녀 동일시 수준은 양육 수행 역량에 어떤 영향을 미치는가?

\section{연구문제 2}

부모-자녀 동일시 수준은 일-자녀교육 갈등과 양육 수행 역량 의 관계에 대해 조절효과가 있는가?

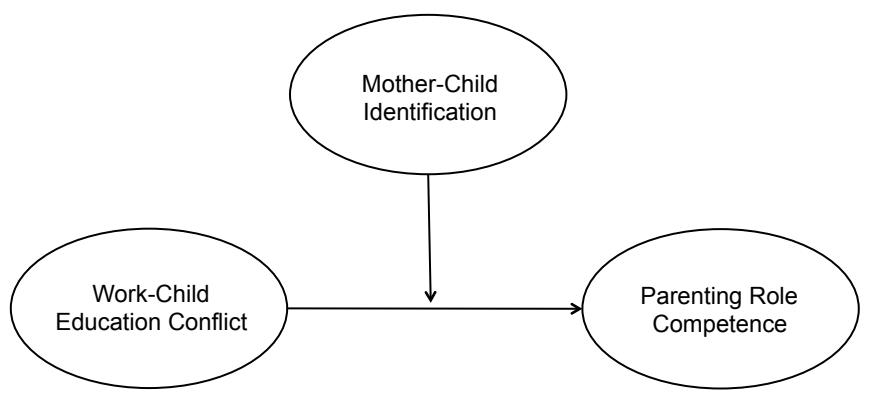

Figure 1. Research model.

\section{Methods}

\section{연구대상}

본 연구는 서울대학교 학부모정책연구센터에서 실시한 학부 모교육참여패널 2차년도(2018년, 초등학교 2학년) 자료를 사 용하였다. 학부모교육참여패널연구는 외국과 구분되는 한국 사회 맥락에서 학부모 교육참여 특징과 관련 요인을 살펴보기 위해 실시되었다(K. Lee, Chin, Lee, \& Kim, 2018). 2017년 3월 초등학교에 입학하는 첫 자녀를 둔 학부모를 대상으로 현재까 지 1차년도(2017년)에는 '입학 전 시기'와 '초등학교 1학년시 기' 2회, 2차년도(2018년)에는 '초등학교 2학년 시기' 1회로 총 3 차례 조사가 실시되었다. 경기, 서울, 인천 지역의 초등학교 1 학년 학생 수에 근거해 총 368 명을 할당표집 하였으며, 이후 초기 표본 이탈로 인해 지역할당과 성비·어머니의 취업여부 비율을 고려하여 165 명을 추가 모집하여 총 533 명을 대상으
로 조사한 패널데이터이다.

본 연구는 초등학교 2학년 취업모의 양육 수행 역량에 관심 을 두었기 때문에 2차년도 자료를 사용하였다. 초등학교 2학 년 학부모 중 현재 재직 중인 취업모 총 155 명을 대상으로 하 였으며, 이들의 평균연령은 39.68세 $(S D=.31)$ 였다. 연구대상 에 대한 자세한 일반적 배경은 Table 1과 같다.

Table 1

Demographic Information of Participants

\begin{tabular}{|c|c|c|}
\hline Variables & Categories & $n(\%)$ \\
\hline \multirow[t]{2}{*}{ Child's gender } & Male & $73(47.1)$ \\
\hline & Female & $82(52.9)$ \\
\hline \multirow{3}{*}{$\begin{array}{l}\text { Maternal academic } \\
\text { background }\end{array}$} & High school graduate & $24(15.5)$ \\
\hline & College graduate & $44(28.4)$ \\
\hline & University graduate & $87(56.1)$ \\
\hline \multirow[t]{2}{*}{ Residential area } & Seoul & $64(41.3)$ \\
\hline & Gyeonggi and Incheon & $91(58.7)$ \\
\hline \multirow[t]{9}{*}{ Maternal jobs } & Sales & $26(16.8)$ \\
\hline & Technical & $3(1.9)$ \\
\hline & Office work & $85(54.8)$ \\
\hline & Service & $29(18.7)$ \\
\hline & Senior management/professional & $8(5.2)$ \\
\hline & Agriculture, forestry, fishery & $0(0)$ \\
\hline & Soldier & $0(0)$ \\
\hline & Simple labor & $4(2.6)$ \\
\hline & Other & $0(0)$ \\
\hline \multirow[t]{2}{*}{ Employment type } & Regular workers & $128(82.6)$ \\
\hline & Temporary $\cdot$ daily workers & $27(17.4)$ \\
\hline \multirow{4}{*}{$\begin{array}{l}\text { Monthly household } \\
\text { income } \\
(10,000 \text { won })\end{array}$} & Less than 399 & $36(23.2)$ \\
\hline & Over 400-499 & $45(29.0)$ \\
\hline & Over 500-599 & $42(27.1)$ \\
\hline & More than 600 & $32(20.6)$ \\
\hline
\end{tabular}

Note. $N=155$.

\section{연구도구}

\section{양육 수행 역량}

양육 수행 역량은 K.-S. Chung과 Choi (2013)가 개발한 부모 참 역량 척도를 학부모교육참여패널이 어머니의 양육역량을 측정하기 위해 일부 발췌하여 사용한 9개의 하위요인 중에서 J. Park 등(2012)이 양육 수행 역량으로 분류한 4개의 하위요인 (민주적 양육, 반응적-공감적 양육, 자녀 생애 진로 개발, 발달 ·학습 지원 환경 제공), 총 12 개 문항만을 사용하여 측정하였 
다. 문항의 예시는 "나는 부모의 권위보다 아이의 입장을 존중 하는 민주적 양육(훈육)에 대해 알고 있다.”, “나는 아이의 속 마음을 읽고, 그에 맞추어 반응하고 공감해준다.", "나는 아이 의 진로와 소질을 개발하는 방법을 실천한다.", "나는 아이의 바른 성장을 위해 더욱 잘 도울 수 있는 방법이 있는지 찾아보 려고 노력한다.” 등이 있으며, 5점 Likert척도(전혀 그렇지 않 다[1] 매우 그렇다[5])로 구성되어있다. 12개 문항의 평균을 어머니의 양육 수행 역량 수준으로 사용하였고, 평균 점수가 높을수록 어머니의 양육 수행 역량감이 높음을 의미한다. 본 연구에서 산출한 Cronbach's $\alpha$ 값은 .81이다.

\section{일-자녀교육 갈등}

일-자녀교육 갈등은 Cinamon과 Rich (2002)가 개발하고 S. Yoo, Hong, Park과 Kim (2012)이 타당화한 '일-가족 갈등 척 도'를 학부모교육참여패널이 연구의 취지를 고려하여 '일-자 녀교육'으로 설문내용을 변경한 척도를 사용하여 측정하였 다. 일-가족 갈등 척도의 하위영역은 일 $\rightarrow$ 가족 갈등 7 문항, 가 족 $\rightarrow$ 일 갈등 7 문항으로 구성되어 있는데, 이를 일 $\rightarrow$ 자녀교 육 7문항, 자녀교육 $\rightarrow$ 일 7문항으로 변경하였다. 해당 척도 는 총 14문항, 5점 Likert척도(전혀 그렇지 않다[1] 매우 그렇 다[5])로 구성되어 있으며, 문항의 예시는 "나는 직장 일을 마 치고 집에 돌아올 때면, 너무 지쳐서 자녀교육에 신경을 쓰 기 어렵다.", “자녀교육을 위한 나의 활동은 직장 일을 방해한 다.” 등이 있다. 14 개 문항의 평균을 어머니의 일-자녀교육 갈 등 수준으로 사용하였고, 평균 점수가 높을수록 어머니의 일자녀교육 갈등 수준이 높음을 의미한다. 본 연구에서 산출한 Cronbach's $\alpha$ 값은 .94 이다.

\section{부모-자녀 동일시}

부모-자녀 동일시는 Shim (2003)이 개발한 심리적 지원을 통 한 교육지원활동 척도 중, 부모-자녀 동일시 하위 요인만 사용 하여 측정하였다. 해당 척도는 총 4문항, 5점 Likert척도(전혀 그렇지 않다[1] 매우 그렇다[5])로 구성되어 있으며, 문항의 예시는 "자녀의 교육을 위해서는 부모가 고생을 감수할 수 있 다고 생각한다.”, “자녀가 일류대학을 간다면 부모로서는 성 공한 것이다.” 등이 있다. 4 개 문항의 평균을 어머니의 부모자녀 동일시 수준으로 사용하였고, 평균 점수가 높을수록 어 머니의 부모-자녀 동일시 수준이 높음을 의미한다. 본 연구에 서 산출한 Cronbach's $\alpha$ 값은 .60이다. 이 수치는 일반적으로 좋
은 수치로 허용되는 .70보다 낮지만, 사회과학분야에서는 .60 이상이면 신뢰도가 있는 것으로 볼 수 있다(George \& Mallery, 2016; J. Song, 2011). 따라서, 분석에 활용하는데 수용할 수 있 는 값으로 판단하고 분석에 사용하였다.

\section{분석방법}

수집된 자료는 SPSS 20.0 (IBM Co., Armonk, NY)과 PROCESS MACRO version 3.4 (Model 1; Hayes, 2017)를 이용하여 분석하 였다. SPSS 프로그램을 이용하여 측정도구들의 신뢰도를 위 해 Cronbach's $\alpha$ 의 값을 산출하고, 기술통계치를 산출하여 연 구대상자와 변인들의 일반적 경향을 살펴보았으며, 주요변인 간의 관계를 파악하기 위해 Pearson의 적률상관분석을 하였다.

취업모의 일-자녀교육 갈등이 양육 수행 역량에 미치는 영향에 대한 부모-자녀 동일시의 조절효과를 검증하기 위해 Baron과 Kenny (1986)가 제시한 절차에 따라 2단계에 걸쳐 위 계적 중다회귀분석을 실시하였다. 1 단계에서는 통제변인과 주요 독립변인을 투입하였다. 투입된 통제변인은 월 평균 가 구소득, 어머니의 학력수준, 어머니의 연령, 아동의 성별이며, 어머니의 학력과 아동의 성별은 더미코딩하여 투입하였다. 2 단계에서는 상호작용항을 모형에 차례로 투입하여 각 단계 에서 변인 추가에 따른 모형의 설명력이 유의미하게 증가하 는지 살펴보았다. 해당 단계에서 발생할 수 있는 다중공선성 의 문제를 줄이기 위하여 독립변인과 조절변인을 평균중심화 (mean centering)하였고, 잔차항들의 상관관계를 확인하기 위 해 Dubin-Watson 값을 산출하였다.

다음으로, 취업모의 일-자녀교육 갈등이 양육 수행 역량에 미치는 영향에 대한 부모-자녀 동일시의 조절효과의 유의성 을 검증하기 위해 PROCESS MACRO 프로그램을 활용하여 Johnson-Neyman 기법으로 조절변수의 유의미한 범위를 구하 고, 단순기울기 검증을 실시하였다. 구체적인 조절효과를 살펴 보기 위해 독립변인과 조절변인의 평균값 \pm 1 표준편차 $(S D)$ 지점 을 기준으로 상·중·하 집단을 구분하여 상호작용의 구체적인 패턴을 그래프로 작성하여 분석하였다(Aiken \& West, 1991).

\section{Results}

\section{연구변인들의 기술통계}

본 연구에서 측정한 변인들은 취업모의 양육 수행 역량, 일-자 
Table 2

Descriptive Statistics for Measured Variables

\begin{tabular}{lcccccr}
\hline & $M(S D)$ & Median & Min & Max & Skewness & Kurtosis \\
\hline Parenting role competence & $3.87(.37)$ & 3.83 & 1 & 5 & .01 & .39 \\
Work-child education conflict & $2.84(.73)$ & 2.93 & 1 & 5 & -.24 & -1.01 \\
Mother-child identification & $3.55(.59)$ & 3.75 & 1 & 5 & -.58 & .65 \\
\hline
\end{tabular}

Note. $N=155$.

Table 3

Correlation Coefficients Among Variables

\begin{tabular}{lcc}
\hline & 1 & 2 \\
\hline 1. Parenting role competence & - & 3 \\
2. Work-child education conflict & $-.23^{* *}$ & - \\
3. Mother-child identification & $.19^{*}$ & $.27^{* * *}$ \\
\hline
\end{tabular}

Note. $N=155$.

${ }^{*} p<.05 .{ }^{* *} p<.01 .{ }^{* * *} p<.001$.

녀교육 갈등, 부모-자녀 동일시이다. 각 변인들의 기술통계치 를 알아본 결과는 Table 2에 제시하였다.

모든 변수는 5점 척도였으며, 취업모의 양육 수행 역량의 문항평균 점수는 3.87점 $(S D=.37)$ 이었고, 중앙치(median)에 가까운 수준이었다. 일-자녀교육 갈등과 부모-자녀 동일시 평 균은 2.84 점 $(S D=.73)$ 과 3.55점 $(S D=.59)$ 으로 각각의 중앙치 보다 약간 낮은 편이었다. 모든 변인의 왜도는 -.58 .01의 값으 로 나타났으며, 첨도는 -1.01 .65값으로 나타났다.

\section{연구변인들 간 상관관계}

취업모의 양육 수행 역량과 일-자녀교육 갈등, 부모-자녀 동일 시 간의 관계를 상관분석을 통해 살펴본 결과, Table 3 과 같다. 이를 살펴보면, 양육 수행 역량은 일-자녀교육 갈등과 유의미한 부적 상관이 있었으며 $(r=-.23, p<.01)$, 부모-자녀 동일시와는 유의미한 정적 상관을 보였다 $(r=.19, p<.05)$. 취업모의 일-자 녀교육 갈등과 부모-자녀 동일시는 유의미한 정적 상관이 있는 것으로 나타났다 $(r=.27, p<.001)$. 즉, 취업모의 일-자녀교육 갈 등이 더 낮거나 부모-자녀 동일시가 높을수록 양육 수행 역량이 높게 나타나는 경향을 보였다. 동시에 일-자녀교육 갈등이 높 을수록 부모-자녀 동일시 수준이 높아지는 경향이 나타났다.

\section{취업모의 일-자녀교육 갈등과 부모-자녀 동일 시 수준이 양육 수행 역량에 미치는 영향}

취업모의 일-자녀교육 갈등과 부모-자녀 동일시 수준이 양육
수행 역량에 미치는 영향을 알아보기 위하여 위계적 중다회귀 분석을 실시하였다. Model 1 회귀모형에서는 통제변인(월 평 균 가구소득, 어머니의 학력수준, 어머니의 연령, 아동의 성별) 과 주요 독립변인을 투입하였고, 투입된 변인들의 공차한계는 .87 .98, $\mathrm{VIF}$ 는 1.02 1.51로 나타나 다중공선성의 문제가 없는 것 을 보여주었다. 또한 잔차항들의 상관관계를 알아보고자 산출 한 Dubin-Watson 값은 2.18로 잔차항 간의 상관관계가 없어 회 귀모형이 적합한 것을 확인하였다. 분석 결과는 Table 4 와 같다.

통제변인과 주요변인을 투입한 Model 1 회귀모형은 유의 미한 것으로 나타났다 $(F=4.44, p<.001)$. 투입된 통제변인과 주요변인들은 취업모의 양육 수행 역량을 $14 \%$ 를 설명하였다. 통제변인 중 어머니의 연령만이 어머니의 취업모의 양육 수 행 역량에 유의미한 정적 영향을 미치는 것으로 나타났다 $(\beta=$ $.18, p<.05)$. 그리고 일-자녀교육 갈등은 취업모의 양육 수행 역량에 유의미한 부적 영향을 $(\beta=-.29, p<.001)$, 부모-자녀 동 일시는 취업모의 양육 수행 역량에 유의미한 정적 영향을 미 치는 것으로 나타났다 $(\beta=.26, p<.01)$. 구체적으로 취업모가 일-자녀교육 양립에 대한 갈등 수준이 높을수록 낮은 양육 수 행 역량감을 경험하였고, 어머니의 연령이 높을수록, 부모-자 녀 동일시 수준이 높을수록 취업모는 높은 양육 수행 역량감 을 경험하였다.

\section{취업모의 일-자녀교육 갈등과 양육 수행 역량의 관계에서 부모-자녀 동일시의 조절효과}

취업모의 일-자녀교육 갈등과 양육 수행 역량의 관계에서 부 
Table 4

Moderating Effect of Mother-Child Identification on the Relationship Between Work-Child Education Conflict and Parenting Role Competence

\begin{tabular}{|c|c|c|c|c|}
\hline & \multicolumn{2}{|c|}{ Model 1} & \multicolumn{2}{|c|}{ Model 2} \\
\hline & $B(S E)$ & $\beta$ & $B(S E)$ & $\beta$ \\
\hline Monthly household income & $.05(.03)$ & .15 & $.06(.03)$ & $.17^{*}$ \\
\hline \multicolumn{5}{|l|}{ Maternal academic background ${ }^{a}$} \\
\hline High school graduate & $-.08(.08)$ & -.08 & $-.10(.08)$ & -.10 \\
\hline College graduate & $.00(.07)$ & .00 & $.01(.06)$ & .02 \\
\hline Mother's age & $.02(.01)$ & $.18^{*}$ & $.02(.01)$ & $.17^{*}$ \\
\hline Child's gender & $-.01(.06)$ & -.01 & $-.01(.06)$ & -.01 \\
\hline Work-child education conflict (A) & $-.15(.04)$ & $-.29^{* * *}$ & $-.16(.04)$ & $-.30^{* * *}$ \\
\hline Mother-child identification (B) & $.17(.05)$ & $.26^{* *}$ & $.23(.06)$ & $.36^{* * *}$ \\
\hline $\mathrm{A} \times \mathrm{B}$ & & & $.18(.08)$ & $.20^{*}$ \\
\hline adj $R^{2}$ & \multicolumn{2}{|c|}{.14} & \multicolumn{2}{|c|}{.16} \\
\hline$\triangle \operatorname{adj} R^{2}$ & & & \multicolumn{2}{|c|}{.02} \\
\hline$F$ & \multicolumn{2}{|c|}{$4.44^{* * *}$} & \multicolumn{2}{|c|}{$4.70^{* * *}$} \\
\hline
\end{tabular}

Note. $N=155$.

${ }^{a}$ reference group $=$ university graduate.

${ }^{*} p<.05 .{ }^{* *} p<.01 .{ }^{* * *} p<.001$.

Table 5

Significance of the Simple Slopes

\begin{tabular}{lccccc}
\hline & & & & \multicolumn{2}{c}{$95 \%$ CI } \\
\cline { 5 - 6 } \multicolumn{1}{c}{ Mother-child identification } & $B$ & $S E$ & $t$ & LL & UL \\
\hline$M-1 S D$ & -.26 & .06 & $-4.19^{* * *}$ & -0.38 & -0.14 \\
$M$ & -.16 & .04 & $-4.00^{* * *}$ & -0.24 & -0.08 \\
$M+1 S D$ & -.06 & .06 & -1.03 & -0.17 & 0.05 \\
\hline
\end{tabular}

Note. $N=155 . M=3.55 ; S D=.59$.

${ }^{* * *} p<.001$.

모-자녀 동일시의 조절효과를 살펴보기 위해 위계적 중다회 귀분석 Model 2에서 일-자녀교육 갈등과 부모-자녀 동일시의 상호작용항을 만들어서 투입하였다. 투입된 독립변인과 상호 작용항의 공차한계는 .69 .98, VIF는 1.03 1.44로 나타나 다중 공선성의 문제가 없는 것을 보여주었다. 또한 잔차항들의 상 관관계를 알아보고자 산출한 Dubin-Watson 값은 2.24로 잔차 항 간의 상관관계가 없어 회귀모형이 적합한 것을 확인하였 다. 분석 결과는 Table 4 에 제시되어있는 바와 같다. 일-자녀교 육 갈등과 부모-자녀 동일시의 상호작용항을 투입한 Model 2 회귀모형은 유의미한 것으로 나타났으며 $(F=4.70, p<.001)$, 상호작용항은 통계적으로 유의한 것으로 나타났다 $(\beta=.20$, $p$ <.05). 투입된 상호작용항은 추가적으로 $2 \%$ 를 설명하며, Model 2의 전체 변인들은 취업모 양육 수행 역량 변인의 총 $16 \%$ 설명하였다.
이러한 조절효과의 유의성을 검증하기 위해 PROCESS MACRO 프로그램을 활용하여 Johnson-Neyman 기법으로 조 절변수의 유의미한 범위를 구하고, 단순기울기 검증을 실시하 였다. Johnson-Neyman 기법을 이용하여 조절변수의 유의미한 범위를 산출한 결과, 부모-자녀 동일시의 점수가 상위 $27.74 \%$ 수준인 3.94점보다 작아질 경우 조절효과가 유의미한 것으로 확인되었다. 이는 동일시 수준이 평균 $(M=3.55)$ 보다 1 표준편 차 $(S D=.59)$ 높은 집단에서는 조절효과가 유의하지 않음을 의 미한다. 이러한 취업모의 부모-자녀 동일시 수준에 따른 효과 크기를 산출하고 통계적 유의성을 살펴보기 위해 실시한 단순 기울기 검정의 결과는 Table 5와 같다(Aiken \& West, 1991). 어 머니의 일-자녀교육 갈등이 양육 수행 역량에 미치는 단순 기 울기는 부모-자녀 동일시 수준이 낮은 집단 $(M-1 S D)$ 에서 -.26 $(t=-4.19, p<.001,95 \% \mathrm{CI}[-0.38,-0.14])$, 평균 집단 $(M)$ 에서 
$-.16(t=-4.00, p<.001,95 \%$ CI $[-0.24,-0.08])$ 으로 통계적으로 유의미하게 부적 증가하였다. 그러나 동일시 수준이 높은 집 단 $(M+1 S D)$ 에서는 효과크기가 유의미하지 않은 것으로 나타 났다 $(B=-.06, t=-1.03$, n.s., $95 \%$ CI $[-0.17,0.05])$. 이는 부모자녀 동일시 수준이 낮은 집단과 평균 집단이 일-자녀교육 갈 등이 양육 수행 역량에 미치는 부적 영향을 더욱 높인다는 것 을 의미하며, 높은 집단에서는 일-자녀교육 갈등이 양육 수행 역량에 유의미한 부적 영향을 미치지 않음을 의미한다.

부모-자녀 동일시 수준에 따른 일-자녀교육 갈등이 취업모 의 양육 수행 역량에 미치는 영향을 구체적으로 살펴보기 위 해 그래프를 그려보면 Figure 2와 같다. Figure 2를 보면 부모자녀 동일시 수준이 낮은 집단의 기울기가 가장 큰 것을 볼 수 있는데, 이는 평균집단에 비해 낮은 집단에서 양육 수행 역량 에 대한 일-자녀교육 갈등의 부적 영향이 더욱 큼을 의미한다. 즉, 조절변인인 부모-자녀 동일시 수준이 높을수록 일-자녀교 육 갈등이 취업모의 양육 수행 역량에 미치는 부정적 영향이 줄어들고, 동일시 수준이 낮을수록 일-자녀교육 갈등이 미치 는 부정적 영향은 더욱 증가하는 것으로 나타났다.

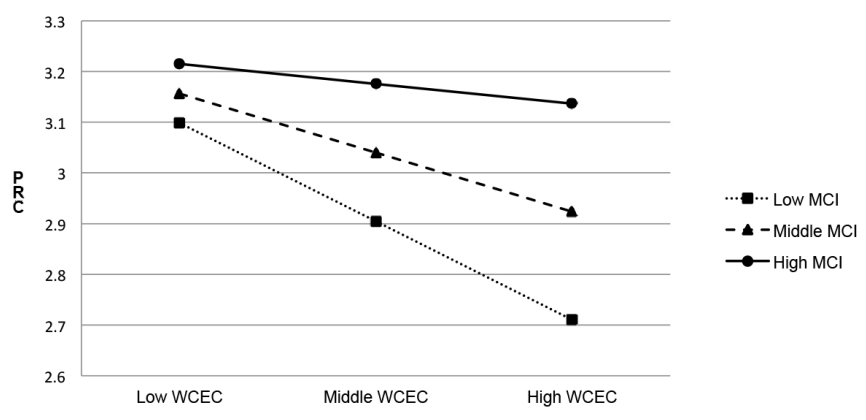

Figure 2. Moderating effects of motehr-child identification on the relationship between work-child education conflict and parenting role competence.

$\mathrm{PRC}=$ parenting role competence; $\mathrm{MCI}=$ mother - child identification; WCEC = work-child education conflict.

\section{Discussion}

본 연구는 초등학교 2학년 자녀를 둔 취업모의 일-자녀교육 갈등과 부모-자녀 동일시 수준이 취업모의 양육 수행 역량에 미치는 영향이 어떠할지 파악하는 데 목적이 있으며, 일-자녀 교육 갈등이 양육 수행 역량에 미치는 관계에서 부모-자녀 동 일시가 조절효과를 갖는지 여부를 파악하는 데 목적이 있다. 그 결과, 취업모가 경험하는 일-자녀교육 갈등이 높을수록 양
육 수행 역량이 낮았으며, 취업모가 인식하는 부모-자녀 동일 시 수준이 높을수록 양육 수행 역량은 높았다. 또한, 일-자녀 교육 갈등과 양육 수행 역량과의 관계에서 부모-자녀 동일시 수준의 조절효과가 나타났다. 즉, 취업모가 일-자녀교육 갈등 을 심하게 경험함에도 불구하고 부모-자녀 동일시 수준이 높 다면, 낮은 부모-자녀 동일시를 보이는 경우에 비하여 상대적 으로 높은 양육 수행 역량을 나타내었다. 본 연구결과를 토대 로 취업모의 일-자녀교육 갈등과 양육 수행 역량, 부모-자녀 동일시의 관계에 따른 함의를 논의하면 다음과 같다.

첫째, 취업모가 경험하는 일-자녀교육 갈등이 높을수록 양 육 수행 역량이 낮았다. 이는 일과 자녀교육을 병행하고 있는 여성들이 다중역할수행에서 비롯되는 과부담으로 인한 것으 로(J. S. Choi, 2011; S. Y. Kim et al., 2011), 취업모가 역할갈등 을 많이 지각할수록 스스로가 평가하는 양육역량이 낮아졌다 는 선행연구와 일치한다(M.-R. Chung et al., 2015). 이러한 결 과는 학부모이자 취업모로서 일과 자녀교육을 병행하는 데 어 려움을 겪고 있는 여성들이 부모로서 적절한 양육 수행 역량 을 획득할 수 있도록 사회적, 제도적인 지원이 필요함을 의미 한다. 특히 초등학교 1 학년 자녀의 학교 적응을 돕기 위해 회 사, 정부 차원에서 받던 혜택이 사라진 초등학교 2학년 학부 모의 경우 양육 부담을 오롯이 부담해야 하는 상황이다. 이에 초등학교 자녀를 둔 엄마의 일-자녀교육 양립을 위해서는 장 시간 근로문화를 개선하는 것도 중요하시만 초등학교 교육시 스템을 변화하는 여성 노동시장의 현실에 맞춰 개선할 필요 가 있다는 주장이 대두되고 있다(Yoon, 2016). 현재 시스템은 초등학교의 짧은 정규 수업 시간을 방과 후 교실과 초등 돌봄 교실로 보충하고 있지만, 2019년 기준 평균 한 학교 당 2.27개 (약 52명) 정도의 소규모로 운영되고 있어서 혜택을 누리지 못 하는 경우도 많다(Ministry of Education, 2020). 또한, 대다수의 돌봄교실은 일반 교실보다 작은 크기의 낙후된 공간에서 이루 어지며 부족한 교사 수급으로 인한 단조로운 프로그램이 문제 로 꼽히기도 한다(E. Lee, 2019). 따라서 취업모의 근로시간과 조화를 이룰 수 있도록 방과 후 교실이나 돌봄교실의 기능을 정규교육시간으로 흡수, 통합함으로써 서비스의 질과 인력의 전문성을 제고할 필요가 있다.

둘째, 취업모가 부모-자녀 관계에 높은 수준의 동일시를 보 일 경우에는 양육 수행 역량이 높았다. 즉, 자녀교육에 있어서 자녀의 성공을 위해 희생을 감내하고자 하는 어머니일수록, 자녀에게 민주적, 공감적 양육을 하며 자녀의 발달과 학습, 진 로를 지원한다는 것이다. 이러한 결과는 자녀에게 정서적 가 치를 많이 부여하는 취업모일수록 부모로서의 역할을 기꺼 
이 수용한다는 선행연구를 지지한다(Y. J. Song et al., 2014). 반 면 지나친 부모-자녀 동일시로 인한 부모의 과다한 기대는 부 모-자녀 관계에서의 갈등과 양육스트레스를 유발할 수 있다 는 선행연구들(J. Han et al. 2013; S. Han, 2008)도 있다. 국외 연구 역시 자녀의 성취에 더 의미를 부여하는 중국인 부모는 미국, 유럽 부모들에 비하여 자녀에 대한 심리적 통제가 강하 고, 자녀의 실패에 덜 온정적으로 반응한다고 보고하였다 $(\mathrm{Ng}$, Pomerantz, \& Deng, 2014; Ng, Pomerantz, Lam, \& Deng, 2019). 그럼에도 불구하고 본 연구 결과에서 부모-자녀 동일시가 양 육 수행 역량과 정적 관계를 보인 이유는 부정적으로 보고한 선행연구들의 대상이 주로 청소년 또는 초기 성인기 자녀로 연령이 높았던 반면, 본 연구 대상의 자녀는 초등학교 2 학년으 로 상대적으로 낮은 연령이었기 때문일 수 있다. 이는 유아기 자녀에 대한 어머니의 미래기대는 높은 수준이었고, 자녀에 대한 미래기대가 높을수록 부모역할 인식수준도 높다는 H.-S. Cho와 $\operatorname{Kim}$ (2013)의 연구결과 맥락을 바탕으로 이해할 수 있 다. 즉, 아직 초등학교 2학년과 같이 연령이 낮은 자녀들에게 는 높은 기대를 가지고 있기에 높은 수준의 부모-자녀 동일시 가 양육 수행 역량에 긍정적 영향을 미칠 수 있다. 반면, 학년 이 증가함에 따라 자녀의 성취를 자신의 성취로 여기는 부모자녀 동일시는 자녀의 진로선택이나 결정에 과도한 개입으로 이어지고, 결국 이는 자녀에게 자율성 저해, 낮은 자립심과 행 복감 등의 부정적 결과를 초래할 수 있다(Jeong \& Yoo, 2015).

따라서 우리나라 문화 특성상 존재하는 높은 수준의 부모자녀 동일시가 학년이 올라감에도 본 연구의 결과와 같이 긍 정적인 요소로 작용하고 과도하게 아동의 결정에 개입하는 것 을 방지하기 위해서는 초등학교 저학년 과정에서부터 의도적 이고 체계적인 학부모를 위한 교육, 특히 진로교육이 필요할 것으로 사료된다. 그러므로 학부모를 위한 진로교육을 통해 부모가 자녀의 강점을 발견하여 자녀가 자신의 진로를 정확히 알도록 도와주어야 한다는 E.-J. Kim (2014)의 주장에 주목해 야 할 필요가 있다. 부모가 자녀의 성취로 자신의 못다 푼 '한' 을 해소하려고 하는 대신, 자녀 자신의 꿈을 이루어 나가는 과 정을 옆에서 응원하고 지원하는 올바른 방법을 알고 실천할 수 있도록 학부모를 지원하는 교육이 학교 차원에서 지속적으 로 이루어져야 한다. 그러나 현재 학교에서 시행되고 있는 학 부모 진로 교육은 학부모 자신이 자녀의 개인적 특성을 파악 하여 지도하기에는 매우 미흡한실정이다. 따라서 부모가 코치 가 되어 자녀의 진로 선택을 지원하는 아동기 진로지도를 위 한 부모코칭 프로그램을 개발하여 적용하는 등의 노력이 필요 하다(E.-J. Kim, 2014).
셋째, 일-자녀교육 갈등과 양육 수행 역량과의 관계에서 부 모-자녀 동일시의 조절효과가 나타났다. 일-자녀교육 갈등이 심한 경우, 부모-자녀 동일시의 수준이 낮을수록 양육 수행 역 량이 낮게 나타났다. 이를 통해 일-자녀교육 갈등을 겪는 취업 모를 위해서는 학교 및 직장, 지역사회 차원에서 자녀와의 유 대 관계를 높일 수 있는 부모교육 및 체험 프로그램을 제공해 주어 자녀를 위해 일하는 것을 기꺼이 여기고 기쁨으로 자녀 를 돌보도록 하는 부모-자녀 동일시를 높여줄 필요가 있다. 반 대로 오히려 높은 부모-자녀 동일시 수준을 보이는 취업모가 그렇지 않은 경우에 비하여 일-자녀교육 갈등을 심하게 경험 함에도 불구하고 상대적으로 높은 양육 수행 역량을 나타내었 다. 즉, 일과 자녀교육의 병행이 어렵고 힘든 상황에도 불구하 고 자녀의 성취를 자신의 성취로 여기고 지원하며 희생을 감 수하려고 노력하는 취업모는 양육 수행 역량마저 높게 유지하 며 1 인 다역을 감당하는 알파걸의 삶을 살아가고 있다는 것이 다. 이러한 취업모는 자신에게 주어진 직장인, 엄마, 학부모 등 의 다양한 역할을 모두 온전하게 수행해 내기 위해서 부단히 노력하고 있음을 예상할 수 있고, 따라서 이들이 이러한 역할 들을 보다 수월하게 감당하도록 지원해 줄 필요성이 있다.

특히 학부모와 교사와의 원활한 소통을 장려하고 학부모의 학교 교육의 이해를 돕기 위해 학부모 학교 참여를 독려하는 요즘과 같은 정책 기조는 모든 것을 온전하게 수행하려는 취 업모에게 부담일 수밖에 없다. 취업모인 학부모들은 바쁜 일 과 속에서 상사의 눈치를 보느라 근무시간 내에 진행되는 각 종 설명회와 상담 등 자녀의 학교활동에 참석하지 못하는 고 충을 해마다 토로하고 있다(S. Kim, 2017). 직장의 사정으로 인 해 참여하지 못하게 되는 경우 역시 학부모로서의 역할을 수 행하지 못했다는 죄책감에 빠질 수 있다. 따라서 학부모의 학 교 참여와 직장생활을 병행할 수 있도록 지원하는 보다 근본 적인 대책이 필요한 실정이다. 이에 ‘학교참여 유급휴가제' 등 을 법제화하여 직장인 학부모의 학교활동 참여를 실질적으로 보장하고 학부모가 아동의 보호자로서 권리와 책임을 다 할 수 있도록 지원 할 필요가 있다. 또한 학교는 학부모의 취업 상 태를 전제로 학교교육지원활동을 계획 하고 동원할 필요가 있 다(Yoon, 2016). 물론 학부모의 학교교육지원활동에서의 적극 적인 참여는 필요하지만, 예산 부족으로 인한 급식이나 청소, 도서관 인력 부족을 부모의 노동력을 이용해 충당한다든가 하 는 정책은 지양할 필요가 있겠다.

마지막으로 본 연구의 제한점과 추후 발전을 위한 방향에 대한 제언은 다음과 같다.

첫째, 논의의 대상을 확대 할 필요가 있다. 본 연구는 취업 
모의 일-자녀교육 갈등이 양육 수행 역량, 부모-자녀 동일시와 의 관계만을 살펴보았다는 한계가 있다. 일-자녀교육 갈등을 제외한 양육 수행 역량과 부모-자녀 동일시와의 관계의 경우 우리나라 문화적 특성이 동일하므로 비취업모는 어떠한 양상 을 보이는지, 취업모와 비교하여 어떠한지 파악할 필요가 있 다. 추후에는 논의의 범위를 확장해서 분석하는 것이 좋을 것 이다. 또한, 본 연구에서는 초등학교 2학년 자녀를 둔 학부모 를 대상으로 살펴보았으나, 논의에서 유추한 것과 같이 더 높 은 연령의 자녀를 가진 경우에는 어떠한 관계성을 보이는지, 만약 부정적 영향을 미치는 결과가 나온다면 그 변곡점이 되 는 연령은 어느 수준인지에 대해 분석할 필요가 있겠다.

둘째, 취업모의 근로형태나 근로시간 등 추가적인 통제변 인을 투입하여 살펴볼 필요가 있다. 근로형태나 근로시간은 취업모의 일-가족생활 양립 어려움 등을 통해 어머니의 양육 수행 역량에 영향을 미칠 수 있다(Moon \& Jang, 2014). 그러나 본 연구에서 사용한 패널데이터에서는 취업모의 근로시간 관 련 자료가 수집되지 않았고, 근로형태 관련 자료는 현저하게 비대칭적으로 수집되어 모형에 투입하여 사용하지 못했다는 한계가 있다. 특히 본 연구에서 통제변인과 주요 변인의 설명 력이 $14 \%$ 로 높지 않은 수준이었던 것을 고려하였을 때, 추후 취업모의 근로형태나 근로시간과 같이 연구대상 관련 통제변 인들을 추가한 포괄적인 연구가 이루어질 필요가 있겠다.

끝으로, 본 연구에서 다룬 일-자녀교육 갈등, 양육 수행 역 량, 부모-자녀 동일시의 관계가 다른 변수들과 어떠한 구조적 관계를 갖는지 살펴 볼 필요가 있다. 본 연구에서는 양육역량 중 양육 기반 역량을 제외하고 양육 수행 역량만을 살펴보았 다는 한계가 있다. 진로교육의 출발이 자녀의 강점을 올바르 게 이해하는 것에 있다면, 자녀의 특성과 발달을 이해하는 양 육 기반 역량은 어떠한 관계를 갖는지 분석할 가치가 있을 것 이다. 또한 부모-자녀 동일시가 양육 역량이 영향을 미치는 경 로에 있어서 선행연구들은 기대, 양육 스트레스 등 다양한 변 수들을 언급하고 있으며(Y.-J. Cho, 2013; S. Y. Han, 2006; Jeong $\&$ Yoo, 2015), 부모의 교육 수준, 사회경제적 지위가 어떠한지, 연령이 어떠한지에 따라 기대와 동일시 수준이 달라지고, 나 아가 실제적 교육에 대한 투자가 달라짐을 보고한 연구도 있 다(K.-A. Kim, 2005). 따라서 추후 연구를 통해 더 의미 있는 결 과를 도출하고자 할 때에는 다양한 요소를 고려한 연구 모델 을 설계하여 경로를 분석하는 과정이 필요하겠다.

본 연구는 일-자녀교육 갈등이 취업모들의 양육 수행 역량 에 미치는 부정적인 영향을 부모가 자녀를 동일시하는 한국의 문화적 양상이 어떻게 조절하는지를 밝히고, 학부모로서의 이
들을 지원하기 위해 어떤 정책적, 사회적 지원이 필요한지에 대해 논의하였다. 이러한 논의들이 모든 것을 잘 감당하고자 노력하는 취업모들에게 실제적인 도움이 되기를 기대한다.

\section{Acknowledgements}

This study was supported by the National Research Foundation of Korea Grant funded by the Ministry of Education (NRF2017S1A5B8A02072579).

\section{Notes}

This article was presented at the 1st Conference of the Panel Study on Korean Parent Educational Involvement in 2019.

\section{Conflict of Interest}

No potential conflict of interest relevant to this article was reported.

\section{References}

\section{In English}

Abidin, R. R. (1992). The determinants of parenting behavior. Journal of Clinical Child Psychology, 21(4), 407-412. doi:10. 1207/s15374424jccp2104_12

Aiken, L. S., \& West, S. G. (1991). Multiple regression: Testing and interpreting interactions. Thousand Oaks, CA: Sage.

Baron, R. M., \& Kenny, D. A. (1986). The moderator-mediator variable distinction in social psychological research: Conceptual, strategic, and statistical considerations. Journal of Personality and Social Psychology, 51(6), 1173-1182. doi:10. 1037/0022-3514.51.6.1173

Duxbury, L., Higgins, C., \& Lee, C. (1994). Work-family conflict: A comparison by gender, family type, and perceived control. Journal of Family Issues, 15(3), 449-466. doi:10.1177/019251394015003006

Furman, W., \& Buhrmester, D. (1992). Age and sex differences in perceptions of networks of personal relationships. Child Development, 63(1), 103-115. doi:10.1111/j.1467-8624.1992. tb03599.x 
George, D., \& Mallery, P. (2016). IBM SPSS statistics 23 step by step: A simple guide and reference (4th ed.). New York: Routledge.

Hayes, A. F. (2017). Introduction to mediation, moderation, and conditional process analysis: A regression-based approach (2nd ed.). New York: Guilford Press.

Murray, M. M., Handyside, L. M., Straka, L. A., \& Arton-Titus, T. V. (2013). Parent empowerment: Connecting with preservice special education teachers. School Community Journal, 23(1), 145-168. Retrieved form ERIC database. (EJ1004336)

Ng, F. F. Y., Pomerantz, E. M., \& Deng, C. (2014). Why are Chinese mothers more controlling than American mothers? "My child is my report card". Child Development, 85(1), 355-369. doi:10.1111/cdev.12102

Ng, F. F. Y., Pomerantz, E. M., Lam, S. F., \& Deng, C. (2019). The role of mothers' child-based worth in their affective responses to children's performance. Child Development, 90(1), e165-e181. doi:10.1111/cdev.12881

\section{In Korean}

Cha, B. J. (2011). The effect of parents' career expectations and highschoolstudents' psychological independence and self-efficacy on career decision-making (Master's thesis). Retrieved from http://www.riss.kr/link?id=T12281311

Cho, A. (2005). A study of prepare measures about lower birthrate: Focused on the change of Korean women's roles (Master's thesis). Retrieved from http://www.riss.kr/link?id= T10363492

Cho, H.-S., \& Kim, M. H. (2013). A study of the organization and effects of a program increasing emotional parenting competency for parents of young children. Early Childhood Education Research \& Review, 17(3), 271-293.

Cho, Y.-J. (2013). Influences of mother's expectation about children's future and parenting stress on the awareness level of parent's role (Master's thesis). Retrieved from http://www.riss.kr/ link?id=T13255212

Choi, I. J. (2006). Cultural psychological implication of the Korea parent-child relationship. The Korea Journal of Counseling, 7(3), 761-773.

Choi, J. S. (2011). A grounded theory research on work-family role conflict-Based on professional women with school aged children. Mental Health \& Social Work, 39, 214-247.

Chung, E. (2019, June 26). Majbeol-i 1 nyeonsae 21 mangagu geubjeung... Janyeo seongjanghalsulog majbeol-i bijung nop-a. nyuseupeulijon [맞벌이 1년새 21만가구 급증 $\cdots$ 자 녀 성장할수록 맞벌이 비중 높아]. Newsfreezone. Retrieved from http://www.newsfreezone.co.kr/news/articleView. html?idxno=117493

Chung, K.-S., \& Choi, E.-S. (2013). A study on the development of $\ulcorner$ authentic parental competence scale $\lrcorner$ for mothers with young children. The Journal of Korea Open Association for Early Childhood Education, 18(3), 225-257.

Chung, K.-S., Goh, E.-K., Park, H.-K., \& Cha, J.-R. (2014). Development of the $\ulcorner$ authentic parental competence scale $\lrcorner$ for mothers with school-age children. Journal of Korean Home Management Association, 32(2), 53-75. doi:10.7466/ JKHMA.2014.32.2.53

Chung, M.-R., Cha, K., Joo, Y., \& Kim, M. (2015). A structural modeling approach to the understanding of relationships among working mothers' role conflict, parenting stress, parenting competency, and flexibility in the workplace. Journal of Future Early Childhood Education, 22(4), 433-454.

Embrain Trend Monitor. (2012). Matbeori gwallyeon josa [맞벌이 관련 조사]. Retrieved from ETM website: https://www. trendmonitor.co.kr

Han, J., Kim, Y., Kim, Y., Seo, J., \& Song, J. (2013). Marriage and family counseling. Seoul: Hakjisa Publisher.

Han, S. (2008). A cultural psychological suggestion for the educational circumstances of Korea. The Korean Journal of Culture and Social Issues, 14(1), 33-46.

Han, S. Y. (2006). The effect of parental expectation and parentadolescent communication on adolescents' achievement motivation (Master's thesis). Retrieved from http://www.riss.kr/ link?id=T10527720

Hong, I. (2017, February 13). Chodeungsaeng eommaneun 2wolbuteo yug-ahyujig 'nunchi jeonjaeng' [초등생 엄마는 2 월부터 육아휴직 '눈치 전쟁']. Seoul Newspaper. Retrieved from http://www.seoul.co.kr/news/newsView.php?id= 20170214010022\&wlog_tag3=naver

Hwang, H.-W., \& Shin, J.-Y. (2009). A study on the role conflict and the quality of life of dual-earner parents. Korean Journal of Family Welfare, 14(1), 45-71.

Jang, P. (2019, February 24). SBS seupesyeol' yeseochaegsang (dwijuchaegsang) 'seuteodikyubeu' tteugeoun ingi... Hagsaengbujonghabjeonhyeong? 'Seukaikaeseul' ibsikodi 'gimjuyeong' mun-ui swaedohaneun iyu ['SBS 스페셜' 예서 책상(뒤주책상) '스터디큐브' 뜨거운 인기...학생부종 합전형? ‘스카이캐슬' 입시코디 '김주영' 문의 쇄도하 는 이유]. Topstarnews. Retrieved from http://www.topstarnews. net/news/articleView.html?idxno=591632

Jeong, Y. J. (1978). A study on the influence of socioeconomic status of parents on their children's school life (Master's thesis). Retrieved from http://www.riss.kr/link?id=T173508

Jeong, Y. J., \& Yoo, G. (2015). The effects of perceived parental expectations for the future careers of children on career decision-making difficulties among undergraduate students: Focusing on the moderating effects of desire for the future jobs in public sector and big business. Family and Culture, 27(3), 39-66. doi:10.21478/family.27.3.201509.002 
Kang, S. (2017, December 15). Jjodeullineun 'gyoyugbi'...Janyeo keogalsulog 'majbeol-i' neul-eonanda [쪼들리는 '교육비'...자녀 커갈수록 ‘맞벌이' 늘어난다]. Joseilbo. Retrieved from http:// www.joseilbo.com/news/htmls/2017/12/20171215341816.html

Kim, A.-N., \& Kwon, Y.-S. (2014). Effect of employed mother's work-mother role conflict on parenting stress: Mediation effect of parental satisfaction. Journal of Digital Convergence, 12(10), 375-384. doi:10.14400/JDC.2014.12.10.375

Kim, E.-J. (2014). The construction and effect of parents coaching program for childhood career guidance. Korean Journal of Family Welfare, 19(4), 975-996.

Kim, J.-M., \& Choi, E.-A. (2018). Meta-analysis research on the trend of parent education program and self-system competency enhancement. Journal of Early Childhood Education \& Educare Welfare, 22(2), 275-305.

Kim, K.-A. (2005). The effects of gender and birth order on parents' expectation of their children's career (Master's thesis). Retrieved from http://www.riss.kr/link?id=T10662221

Kim, M. S. (2005). The effects of parenting stress and parenting efficacy on parenting behavior among mothers: The case of those with preschoolers and school-aged children (Master's thesis). Retrieved from http://www.riss.kr/link?id=T10538146

Kim, S. (2017, April 4). Johuiyeon gyoyuggam 'haggyo chamyeo yugeubhyugaje' bojang [조희연 교육감 '학교 참여 유 급휴가제' 보장]. Newsedu. Retrieved from http://www. newsedu.co.kr/news/articleView.html?idxno=50163

Kim, S.-M. (2005). Dual earner families' child care alternatives and policy implications. Journal of Korean Home Management Association, 23(6), 105-116.

Kim, S. Y., Kim, S., \& Lee, K. (2011). A qualitative study on dual earner families' work and family lives for ideal work-family balance. Journal of Korean Family Resource Management Association, 15(1), 93-116.

Lee, C. (2018, February 26). Chodeung ibhag adongbumo, 10si chulgeunhaedo jeongbujiwon badneunda [초등 입학 아 동부모, 10 시 출근해도 정부지원 받는다]. Asiaeconomy. Retrieved from http://view.asiae.co.kr/news/view.htm?idxno= 2018022414302592786

Lee, C. S. (2011). The effect of parental career expectation and parental career-related support, on career attitude maturity of high-school students-The effect psychological independence(Master's thesis). Retrieved from http://www.riss.kr/link?id= T12639066

Lee, E. (2019, December 4). “Dolboji moshaneun dolbomgyosil”... Chodeungdolbomgyosil-ui siltae ["돌보지 못하는 돌봄교 실”...초등돌봄교실의 실태]. Yonhapnews. Retrieved from https://www.yna.co.kr/view/AKR20191203136900797?in put $=1195 \mathrm{~m}$

Lee, K., Chin, M., Lee, J., \& Kim, Y. (2018). Elementary school chogijeogeunggi hakbumoui gyoyukchamyeo yeongu [초등학교
초기적응기 학부모의 교육참여 연구](Report No. 201801). Retrieved from Center For Family-School Partnership Policy Research at Seoul National University website: http://family-school.snu.ac.kr

Ministry of Education. (2020). Chodeungdolbomgyosil un-yeong hwagdae deung-eulo sinhaggi dolbom jiwon ganghwa [초등돌 봄교실 운영 확대 등으로 신학기 돌봄 지원 강화]. Retrieved from MOE website: https://moe.go.kr

Moon, E.-Y., \& Jang, M.-S. (2014). Difficulties of work-family life balance of working parents and the policies of Seoul city-Focusing on non-regularly employed working moms. Journal of Public Society, 4(1), 5-36.

Park, B. S., \& Um, M. Y. (2016). The effects of working mother's work-family role conflict on child-rearing attitudes. Korean Journal of Family Social Work, 54, 7-39.

Park, H. J., \& Moon, H. J. (2012). The effects of motther's guilty conscience and parenting stress on parenting behavior. Journal of Korean Care and Education, 8(2), 121-137.

Park, J., Seo, B., \& Kim, E. (2013). The study on parental competence of mothers of children with disabilities. Special Education Research, 12(3), 179-202.

Shim, M. O. (2003). Parent educational supporting activities for their children. The Journal of Elementary Education, 16(2), 333-358.

Song, J. (2011). Nonmunjakseonge piryohan SPSS/AMOS tonggyebunseokbangbeop [논문작성에 필요한 SPSS/AMOS 통계분석방법]. Paju, KR: 21C Books.

Song, Y. J., Lee, M. R., \& Chun, H. Y. (2014). Parenting stress changes in both of continuous working and non-working mothers after the birth of their first child: A focus on the effects of the values, knowledge and expectations about their children. Korean Journal of Child Studies, 35(5), 1535. doi:10.5723/KJCS.2014.35.5.15

Statistics Korea. (2015). 2015nyeon 4/4bungi mit yeongan gagyedonghyang [2015년 4/4분기 및 연간 가계동향]. Retrieved from Statistics Korea website: https://kostat.go.kr

Statistics Korea. (2019). 2018nyeon habangi jiyeogbyeolgoyongjosa (bugahangmog) majbeol-i gagu mich lin gagu goyong hyeonhwang [2018년 하반기 지역별고용조사(부가항목) 맞벌이 가구 및 1 인 가구 고용 현황]. Retrieved from Statistics Korea website: http://kostat.go.kr

Yoo, M. (2014). Effects of marriage teachers' work-family role conflicts on child rearing stress and job stress (Master's thesis). Retrieved from http://www.riss.kr/link?id=T13358180

Yoo, S., Hong, S., Park, J., \& Kim, S. (2012). A validation study of the work-family conflict scale with Korean women. Korean Journal of Woman Psychology, 17(1), 1-29.

Yoon, J. (2016). Mothers' educational support activities and employment. The Journal of Women and Economics, 13(2), 183-212. 


\section{ORCID}

$\begin{array}{ll}\text { Eun Hwa Jeong } & \text { http://orcid.org/0000-0001-8448-920X } \\ \text { Ji Young Kim } & \text { http://orcid.org/0000-0002-7190-6569 } \\ \text { Hyun A Lee } & \text { http://orcid.org/0000-0002-0733-1772 } \\ \text { Kangyi Lee } & \text { http://orcid.org/0000-0002-1193-5771 }\end{array}$

Received February 29, 2020

Revision received March 30, 2020

Accepted April 13, 2020 